ARTIGO

DOI: https://doi.org/10.22481/praxis.v14i29.4117

\title{
TAREFA MATEMÁTICA PARA EDUCAÇÃO FINANCEIRA: UMA DISCUSSÃO À LUZ DA EDUCAÇÃO MATEMÁTICA REALÍSTICA
}

\author{
MATHEMATICAL TASK FOR FINANCIAL EDUCATION: A DISCUSSION IN THE \\ LIGHT OF REALISTIC MATHEMATICAL EDUCATION
}

TAREA MATEMÁTICA PARA LA EDUCACIÓN FINANCIERA: UNA DISCUSIÓN A
LA LUZ DE LA EDUCACIÓN MATEMÁTICA REALÍSTICA

Daniela Harmuch

Universidade Estadual de Londrina - Brasil

Marcele Tavares Mendes

Universidade Tecnológica Federal do Paraná - Brasil

\begin{abstract}
Resumo: Neste artigo apresentamos uma discussão a respeito do desenvolvimento de competências e objetivos da Educação Financeira a partir de uma tarefa que suscita a utilização de ideias matemáticas. A discussão aqui provocada é um recorte de uma pesquisa de mestrado, de natureza qualitativa de cunho interpretativo, a qual buscou elaborar, aplicar e discutir uma Sequência de Tarefas para uma Educação Financeira à luz da abordagem de ensino Educação Matemática Realística. Em particular, a tarefa analisada envolve contextos em que é preciso realizar cálculos envolvendo porcentagens para tomadas de decisão e escolhas conscientes. As nossas reflexões são subsidiadas pela análise de áudios e da produção escrita de alunos de uma instituição filantrópica da cidade de Londrina-PR, em oficinas de aprendizagem desenvolvidas no segundo semestre de 2016. Em nossa análise, pudemos inferir que a matemática se comportou como um meio de organizar situações da Educação Financeira e que os contextos envolvidos, como a condução do desenvolvimento da discussão da tarefa, favoreceram aos alunos desenvolver competências da Educação Financeira apresentadas nos documentos do Enef e nas diretrizes nacionais de educação, assim como competências de um sujeito matematicamente letrado.
\end{abstract}

Palavras-chave: Educação Matemática. Educação Financeira. Tarefas.

\begin{abstract}
In this article we present a discussion about the development of competences and objectives of Financial Education from a task that raises the use of mathematical ideas. The discussion here provoked is a cut of a master's research, of a qualitative nature of an interpretative nature, which sought to elaborate, apply and discuss a sequence of tasks for a financial education in the light of the teaching approach Realistic Mathematical Education. In particular, the task analyzed involves contexts where it is necessary to perform calculations involving percentages for decision-making and conscious choices. Our reflections are subsidized by the analysis of audios and the written production of students of a philanthropic institution of the city of Londrina-PR, in learning workshops developed in the
\end{abstract}


second half of 2016. In our analysis, we could infer that mathematics behaved as a to organize Financial Education situations and that the contexts involved, such as the conduct of the discussion of the task, favored the students to develop Financial Education competencies proposed in the Enef documents and in the national education guidelines, as well as competences of a subject mathematically literate.

Keywords: Mathematics Education. Financial Education. Tasks.

Resumen: En este artículo presentamos una discusión acerca del desarrollo de competencias y objetivos de la Educación Financiera a partir de una tarea que suscita la utilización de ideas matemáticas. La discusión aquí provocada es un recorte de una investigación de maestría, de naturaleza cualitativa de cuño interpretativo, la cual buscó elaborar, aplicar y discutir una Secuencia de Tareas para una Educación Financiera a la luz del enfoque de enseñanza Educación Matemática Realista. En particular, la tarea analizada implica contextos en los que es necesario realizar cálculos que involucren porcentajes para tomas de decisión y elecciones conscientes. Nuestras reflexiones son subsidiadas por el análisis de audios y la producción escrita de alumnos de una institución filantrópica de la ciudad de Londrina-PR, en talleres de aprendizaje desarrollados en el segundo semestre de 2016. En nuestro análisis, pudimos inferir que las matemáticas se comportaron como un " el medio de organizar situaciones de la Educación Financiera y que los contextos involucrados, como la conducción del desarrollo de la discusión de la tarea, favorecieron a los alumnos desarrollar competencias de la Educación Financiera propuesta en los documentos del Enef y en las directrices nacionales de educación, así como competencias de un sujeto matemáticamente leer y escribir.

Palabras clave: Educación Matemática. Educación Financiera. Tareas.

\section{Introdução}

Este artigo discute uma tarefa matemática que faz parte de uma Sequência de Tarefas elaborada ao longo da pesquisa de mestrado da primeira autora, com a orientação da segunda autora, no Programa de Pós-Graduação em Ensino de Matemática, da Universidade Tecnológica Federal do Paraná, Londrina/Cornélio Procópio. A pesquisa de mestrado tinha como objetivo geral elaborar, aplicar e discutir tarefas matemáticas que provocam reflexões a respeito de temas da Educação Financeira à luz da abordagem de ensino Educação Matemática Realística. A aplicação da Sequência de Tarefas foi no segundo semestre de 2016, em uma instituição filantrópica de Londrina - PR, cujos alunos são jovens em situação de desproteção social ${ }^{1}$.

\footnotetext{
${ }^{1}$ O Estatuto da Criança e do Adolescente (ECA), Lei ${ }^{\circ} 8.069$, de 13 de julho de 1990, que dispõe sobre a proteção integral à criança e ao adolescente, estabelece que crianças e adolescentes são considerados sujeitos de direitos, que vivenciam condições especiais e particulares, cujo desenvolvimento físico, mental, moral e social deve ser garantido em condiçães de liberdade e de dignidade. Adolescente em situação de desproteção social é aquele em que esses direitos não são garantidos.
} 
Ao elaborar o conjunto de tarefas (Sequência de Tarefas), buscou-se por situações e contextos que favorecessem ao aluno a oportunidade de desenvolver/construir elementos de um pensamento financeiro autônomo e saudável. Tanto ao elaborar as tarefas, como em sua aplicação foram considerados os princípios da abordagem de ensino Educação Matemática Realística $\left(\mathrm{RME}^{2}\right)$.

A RME surgiu na Holanda no final da década de 60 e foi inspirada, principalmente, nas ideias e contribuições de Hans Freudenthal (1905-1990). Para ele, a matemática é uma atividade humana - uma atividade natural e social que se transforma à mediada que a humanidade evolui (FREUDENTHAL, 1971). Nessa abordagem, o professor guia e acompanha os processos de aprendizagem de seus estudantes; o aluno é protagonista da construção de seus conhecimentos, a aprendizagem se dá por meio do lidar com situações em que os conceitos e estruturas matemáticas (conhecimentos) tornam-se ferramenta (MENDES, 2014; HARMUCH, 2017).

Os princípios e competências da Educação Financeira abordada têm como base os apresentados pela $\mathrm{OCDE}^{3}$ em um modelo pedagógico concebido

[...] para oferecer ao aluno informações e orientações que favoreçam a construção de um pensamento financeiro consistente e o desenvolvimento de comportamentos autônomos e saudáveis, para que ele possa, como protagonista de sua história, planejar e fazer acontecer a vida que deseja para si próprio, em conexão com o grupo familiar e social a que pertence. Nesse sentido, o foco do trabalho recai sobre as situações cotidianas da vida do aluno, porque é nelas que se encontram os dilemas financeiros. (BRASIL/COREMEC, 2010, p.7).

De modo restrito, neste artigo, discutimos uma das tarefas elaboradas no intuito de evidenciar que os contextos envolvidos, como sua condução à luz dos princípios da RME, favoreceram que os alunos desenvolvessem competências da Educação Financeira, assim como competências de um sujeito matematicamente letrado.

Para tanto, como ponto de partida, apresentamos em duas seções subsequentes pressupostos da Educação Matemática Realística e da Educação Financeira. Em seguida, destacamos os aspectos dos procedimentos metodológicos considerados no desenvolvimento da pesquisa, em particular da tarefa destacada. Subsidiada na construção teórica, apresentamos uma discussão a partir de produções dos alunos ao lidar com a tarefa

\footnotetext{
${ }^{2}$ Do Inglês, RealisticMathematicsEducation.

${ }^{3}$ Organização para Cooperação e Desenvolvimento Econômico (OCDE).
} 
selecionada. Encerramos com nossas considerações finais, seguidas das referências bibliográficas.

\section{A Educação Matemática Realística}

A RME ascende-se na década de 60, em uma direção distinta à direção do formalismo da Matemática Moderna. O saber matemática, nessa perspectiva, significa reconhecer-se matematicamente letrado. Em outras palavras, matematicamente letrado referese à capacidade de "identificar e compreender o papel que a matemática desempenha no mundo, de fazer julgamentos bem fundamentados, e de usar a Matemática de modo a atender as suas necessidades presentes e futuras como cidadão construtivo, interessado e reflexivo" (De LANGE, 2003, p.76).

Nessa abordagem, o ensino não se inicia a partir de definições, fórmulas, teoremas e propriedades apresentadas pelo professor. A concepção de ensino em que o professor restringe sua ação a tentar estabelecer conexões entre o que o aluno já sabe e o corpo exterior do conhecimento matemático que ele precisa "adquirir" é criticada (GRAVEMEIJER, 2005). Pressupõe-se um aluno que, em vez de "adquirir", constrói um conhecimento, uma matemática a partir de sua experiência e entendimento de mundo ao lidar com situações, isto é, os alunos "deveriam repetir o processo de aprendizagem da humanidade, não como isso de fato ocorreu, mas, sim, como ele teria sido feito se as pessoas no passado tivessem conhecido um pouco mais do que nós sabemos agora” (FREUDENTHAL, 1991, p.48).

Reconhecida como uma atividade humana, a matemática é

[...] uma atividade de resolver problemas, de procurar problemas, e também uma atividade de organização de um assunto. Esta pode ser uma questão da realidade, a qual tem de ser organizada de acordo com padrões matemáticos se tiver de ser resolvida. Também pode ser uma questão matemática, resultados novos ou velhos de produção própria ou de outros, que têm de ser organizados de acordo com novas ideias, para ser [mais bem] entendida, em um contexto mais amplo ou por uma abordagem axiomática. (FREUDENTHAL, 1971).

Ao encontro do que já foi apresentado, a matemática torna-se um meio de organizar uma situação e deve ser conectada à realidade para que possa ser de valor humano (VAN DEN HEUVEL-PANHUIZEN, 2001). Aos estudantes deve ser dada a oportunidade "guiada" para "re-inventá-la" (FREUDENTHAL, 1979; VAN DEN HEUVEL-PANHUIZEN, 1996). Reinventá-la no sentido de permitir que o aluno, guiado pelo professor, se sinta o sujeito que 
elaborou/desenvolveu as estratégias, procedimentos, recursos matemáticos para lidar com uma situação. O professor tem papel fundamental nesse processo, uma vez que é ele que decide os momentos de intervir e de promover sistematizações das ideias matemáticas envolvidas.

Esse processo de guiar e acompanhar o reinventar a construção do conhecimento dos alunos é denominado de Reinvenção Guiada, uma estratégia de ensino desenvolvida a partir da análise e da interpretação da matemática como uma atividade humana (FREUDENTHAL, 1991). Segundo Santos (2014), uma aula sob a estratégia da Reinvenção Guiada tem início com a proposição de uma tarefa realística ${ }^{4}$ que possibilita diferentes níveis de matematização, podendo ser proposta individualmente ou em grupos. Após resolverem a tarefa, os alunos podem interagir uns com os outros e terem a oportunidade de analisar e discutir as estratégias e os procedimentos que utilizaram. Durante e após o trabalho dos alunos, o professor pode fazer questionamentos para explorar as resoluções que apresentaram, bem como as diferenças existentes entre elas, e discutir aspectos matemáticos subjacentes a essas resoluções encorajando-os a se interessar por esses aspectos.

$\mathrm{Na}$ Reinvenção Guiada, a tarefa é a "matéria-prima" de todo o processo de aprendizagem desenvolvido em uma sala de aula. O esquema da Figura 1 elenca algumas de suas potencialidades.

Figura1: Potencialidades de uma tarefa na perspectiva da RME

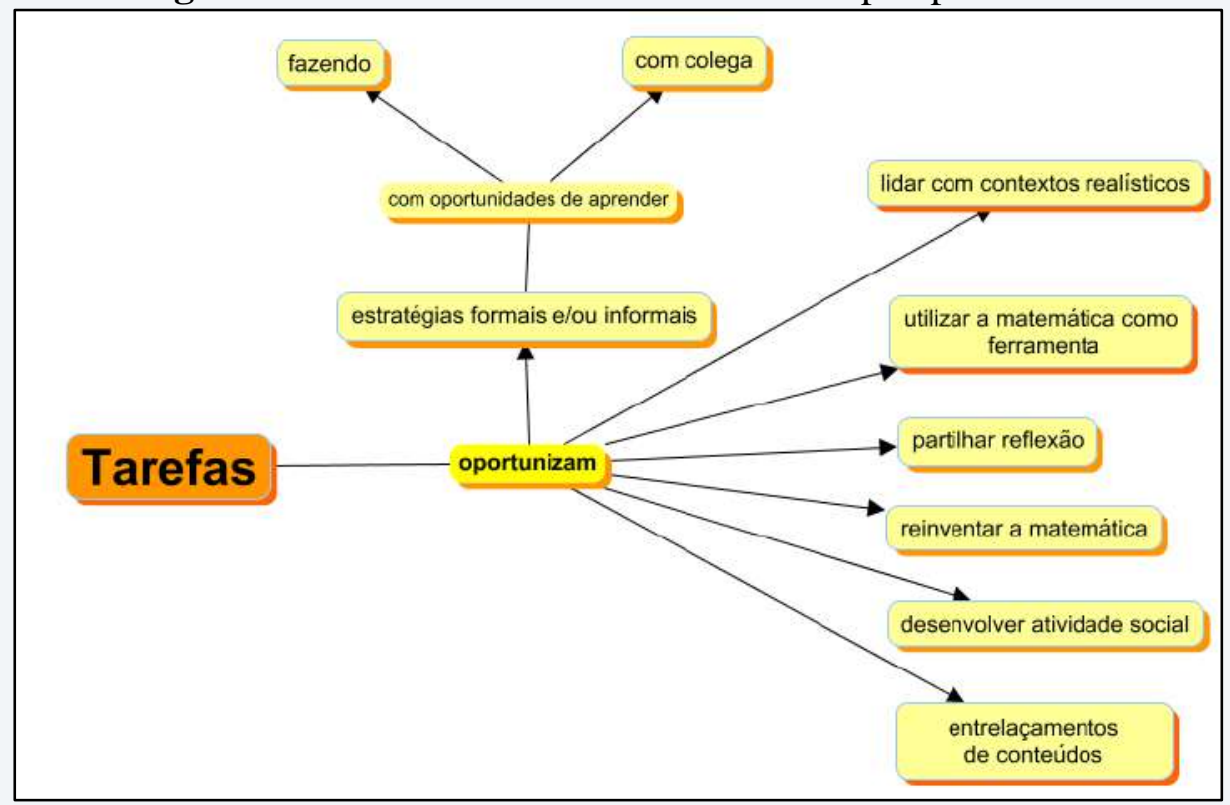

Fonte: (HARMUCH, 2017 p. 27)

\footnotetext{
${ }^{4}$ Realística não advém necessariamente da realidade. Realístico é que pode ser imaginável, realizável pelo estudante (MENDES, 2014).
} 
Conforme Ciani (2012), os alunos devem lidar com situações que favorecem a utilização de diferentes estratégias (informais e formais). Por meio dessas situações, eles começam por analisar contextos que podem ser matematizados, de modo que sejam preparados para usar a matemática na formulação e resolução de situações (problemas, tarefas). Além do mais, o lidar com essas situações favorece que os conteúdos curriculares não sejam trabalhados em capítulos estanques, uma vez que vários conhecimentos e ferramentas matemáticas podem ser utilizados.

À luz desses pressupostos de matemática, de ensino e de aprendizagem, propusemonos a organizar tarefas matemáticas que fossem "realizáveis" para que, guiados pelo professor, os alunos possam construir conceitos formalizados referentes à Educação Financeira, uma vez que a atividade econômica tem seu destaque entre os diversos fenômenos que necessitam de ideias e de conceitos matemáticos enquanto recursos para seu entendimento e desenvolvimento. Essas tarefas podem ser encontradas em Harmuch (2017).

\section{Que Educação Financeira?}

Tanto as mudanças no cenário brasileiro, no que concerne especificamente às constantes alterações econômicas e mudanças, como, por exemplo, do sistema previdenciário, da reforma trabalhista, que exigem uma visão em longo prazo, quanto antecipar um endividamento ou seu próprio controle da situação financeira, desconforto pelo qual milhões de brasileiros passaram ou estão passando , fruto de más escolhas ou falta de planejamento, são circunstâncias que têm solicitado dos cidadãos o desenvolvimento de competências que lhes permitam tais gerenciamentos. A Educação Financeira é uma aliada nessa direção.

Lidar com assuntos da Educação Financeira em aulas de matemática faz-se pertinente e necessário, sobretudo no esforço de promover o conhecimento matemático escolar, conferir significados econômicos aos problemas matemáticos e vice-versa, explorando-se bidirecionalmente a importância do contexto na construção de sentido e na solução de problemas (HOFMAN; MORO, 2011).

Os princípios orientadores da Educação Financeira que consideramos neste trabalho baseiam-se nos documentos da Estratégia Nacional de Educação Financeira (ENEF) cujo objetivo é educar crianças e adolescentes para lidar com o uso do dinheiro de maneira consciente de modo que desenvolvam hábitos e comportamentos desejáveis. Esse documento, 
ENEF (2011) sugere um modelo pedagógico com objetivos que envolvem duas dimensões, espacial e temporal, uma vez que o cotidiano acontece sempre em um espaço e um tempo determinados.

O Quadro 1 a seguir apresenta os sete objetivos desse modelo, separados nas duas dimensões mencionadas e ramificados em dez competências.

Quadro 1 - Objetivos e competências da Educação Financeira

\begin{tabular}{|c|c|c|c|c|}
\hline \multicolumn{3}{|c|}{ OBJETIVOS } & \multicolumn{2}{|c|}{ COMPETÊNCIAS } \\
\hline \multirow{4}{*}{ 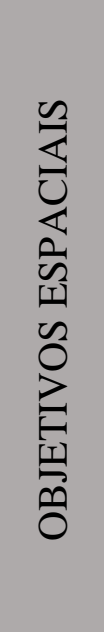 } & OB1 & Formar para a cidadania. & $\mathrm{C} 01$ & Debater direitos e deveres. \\
\hline & OB2 & $\begin{array}{l}\text { Ensinar a consumir e a } \\
\text { poupar de modo ético, } \\
\text { consciente e responsável. }\end{array}$ & $\begin{array}{l}\mathrm{C} 02 \\
\mathrm{C} 03\end{array}$ & $\begin{array}{l}\text { Tomar decisões financeiras social e } \\
\text { ambientalmente responsáveis. } \\
\text { Harmonizar desejos e necessidades } \\
\text { no planejamento financeiro do } \\
\text { projeto de vida. }\end{array}$ \\
\hline & OB3 & $\begin{array}{l}\text { Oferecer conceitos e } \\
\text { ferramentas para tomada de } \\
\text { decisão autônoma baseada em } \\
\text { mudança de atitude. }\end{array}$ & $\begin{array}{l}\mathrm{C} 04 \\
\mathrm{C} 05 \\
\mathrm{C} 06\end{array}$ & $\begin{array}{l}\text { Ler e interpretar textos específicos de } \\
\text { Educação Financeira. } \\
\text { Ler criticamente textos publicitários. } \\
\text { Tomar decisões financeiras } \\
\text { autônomas de acordo com suas reais } \\
\text { necessidades. }\end{array}$ \\
\hline & OB4 & Formar multiplicadores. & $\mathrm{C} 07$ & Atuar como multiplicador. \\
\hline \multirow{3}{*}{ 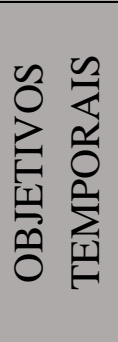 } & OB5 & $\begin{array}{l}\text { Ensinar a planejar em curto, } \\
\text { médio e longo prazos. }\end{array}$ & $\mathrm{C} 08$ & Elaborar planejamento financeiro. \\
\hline & OB6 & $\begin{array}{l}\text { Desenvolver a cultura da } \\
\text { prevenção. }\end{array}$ & $\mathrm{C} 09$ & $\begin{array}{l}\text { Analisar alternativas de prevenção } \\
\text { em longo prazo. }\end{array}$ \\
\hline & OB7 & $\begin{array}{l}\text { Proporcionar a possibilidade } \\
\text { de mudança da condição } \\
\text { atual. }\end{array}$ & $\mathrm{C} 10$ & $\begin{array}{l}\text { Analisar alternativas para superar } \\
\text { dificuldades econômicas. }\end{array}$ \\
\hline
\end{tabular}

Fonte: (BRASIL/COREMEC, 2010, p. 6)

A partir do documento, entendemos que o objetivo um, Formar para a cidadania, propõe a necessidade de, em contexto de sala de aula, discutir direitos e deveres do cidadão, para que ele reconheça seu papel na vida pública, política e de sua comunidade.

No objetivo dois, Ensinar a consumir e a poupar de modo ético, consciente e responsável, sugere-se que contextos que remetem à necessidade de um consumo em níveis adequados são pertinentes em tarefas de sala de aula, visto que podem favorecer que o consumo seja uma prática ética, consciente, responsável e equilibrada. Especificamente, significa discutir contextos em que se provoca uma reflexão a respeito de adquirir produtos advindos de relações de exploração ou de empresas sem comprometimento socioambiental, de 
reduzir o consumo desnecessário, de ampliar a longevidade dos produtos possuídos, de reduzir a produção de lixo e de doar objetos úteis não (BRASIL/ENEF, 2010).

Numa sociedade em que a maioria das pessoas é marcada pelo consumo, e em que se estimulam emoções que levam ao consumo exagerado, em vez de cultivar o uso da razão, é necessário abordar, no ambiente escolar, julgamentos críticos em relação à publicidade e buscar decisões financeiras de acordo com suas reais necessidades, objetivo três, ou seja, oferecer conceitos e ferramentas para a tomada de decisão autônoma baseada em mudança de atitude.

Se em um contexto escolar houver uma conscientização dos alunos em relação à tendência consumidora da sociedade, talvez possa haver mudanças nos contextos familiares, e as escolas exerçam a função de formar disseminadores, objetivo quatro.

A falta de planejamento e a sensação de que o presente não se relaciona com o passado nem com o futuro fazem com que o tempo seja pulverizado numa multiplicação de “eternos instantes" acidentais e episódicos (BRASIL/ENEF, 2010). A atividade de planejar a curto, médio e longo prazo em contexto escolar faz-se necessária, objetivo cinco.

Pensando nas intempéries da vida, é fundamental buscar planejamentos uma vez que ninguém está isento de enfrentar situações adversas e inesperadas do dia a dia, que, por vezes, podem exigir gasto de uma quantia de dinheiro não prevista no orçamento doméstico. Assim, é desejável desenvolver a cultura de prevenção, objetivo 6.

Reconhecer cada estudante em estado de constante evolução (desenvolvimento) e ter a prática de analisar os possíveis encaminhamentos para cada situação pode proporcionar possibilidade de mudança da condição atual, objetivo 7. Especificamente com relação à Educação Financeira, analisar alternativas para superar dificuldades econômicas contribui, "também, para criar ou aumentar o excedente, possibilitando a realização de planos de longo prazo que, em última análise, trazem mais benefícios sociais” (BRASIL/ENEF, 2010, p.14).

As competências que derivam dos objetivos sugeridos no Quadro 1 não têm a mesma ordem de importância e isso é intencional, porque umas são basilares, outras um pouco mais periféricas, e há múltiplas relações das competências entre si.

\section{$O$ contexto da pesquisa e da tarefa discutida}

Os aspectos metodológicos aqui apresentados serviram a uma pesquisa qualitativa de cunho interpretativo, cujo objetivo era elaborar, aplicar e discutir tarefas matemáticas que 
provocam reflexões a respeito de temas da Educação Financeira à luz da abordagem de ensino Educação Matemática Realística. Ao final da pesquisa, formou-se um conjunto de 12 tarefas, que foram organizadas como uma Sequência de Tarefas e que podem ser consultadas em Harmuch (2017). São apresentados, também, uma possível dinâmica de organização pedagógica à luz dos pressupostos da RME, objetivos e competências - Quadro 1 - que poderão ser trabalhados, assim como uma previsão de possíveis produções de alunos.

A aplicação da Sequência de Tarefas ocorreu em uma instituição filantrópica de Londrina - PR, no segundo semestre de 2016, em três oficinas de 4 horas. O principal objetivo do trabalho realizado pela instituição é promover o direcionamento social, educacional e profissional do adolescente, qualificando-o para o mercado de trabalho e visando a transformação de sua realidade. Atualmente os cursos ofertados na Aprendizagem Profissional ${ }^{5}$ são: Auxiliar Administrativo e Operador do Comércio e Varejo.

A pesquisa teve como sujeitos 24 jovens em desproteção social, de diferentes regiões da cidade, que cursam do $9^{\circ}$ ano do Ensino Fundamental ao $3^{\circ}$ ano do Ensino Médio, e que no contraturno de suas atividades escolares, são alunos dessa instituição. O Quadro 2 apresenta o Tema de cada uma das oficinas realizadas, com o respectivo número das tarefas trabalhadas em cada encontro.

Quadro 2: Temas e Organização das Tarefas

\begin{tabular}{|l|l|l|}
\hline Organização & Tema & Tarefas \\
\hline Oficina 1 & $\begin{array}{l}\text { A busca do conceito de felicidade - uma reflexão do } \\
\text { custo de vida e estratégias de economia doméstica. }\end{array}$ & $\begin{array}{l}\text { Tarefas 1, 2, 3, 4 e } \\
5\end{array}$ \\
\hline Oficina 2 & $\begin{array}{l}\text { Gastos pequenos precisam ser controlados, eles se } \\
\text { acumulam e podem tornar gastos grandes. }\end{array}$ & Tarefas 6, 7, 8, 9 \\
\hline Oficina 3 & $\begin{array}{l}\text { Como devo agir em situações reais diversas } \\
\text { relacionadas ao quesito financeiro? }\end{array}$ & Tarefas 10, 11 e 12 \\
\hline
\end{tabular}

Fonte: (HARMUCH, 2017)

Os dados são fruto das gravações de áudio transcritas, fotos e diário de campo, com o consentimento legal dos alunos, de seus responsáveis e da Instituição. Neste texto apresentamos e discutimos a Tarefa 11 , desenvolvida com os sujeitos da pesquisa na terceira oficina, na qual a primeira autora foi a regente da oficina. No presente artigo, cada aluno foi designado pela letra A seguida de um número de 1 a 24 e a professora por P.

\footnotetext{
${ }^{5}$ Dados de 2017.
} 
A Tarefa organizada para a realização em grupo foi composta por cinco fichas com situações que requeriam lidar com cálculos que envolvessem o conceito de porcentagem. A dinâmica proposta consistiu em cada grupo de alunos escolher uma das 5 fichas para resolver e, à medida que a concluíssem, escolheriam outra e, assim sucessivamente, até que todos os grupos lidassem com as cinco situações. A cada grupo foi dado um tempo máximo de 15 minutos para expor a forma de pensar. Cada grupo deveria apresentar pelo menos duas soluções distintas registradas em papel. Ao final da dinâmica, em roda de discussão, refletiuse a respeito das soluções apresentadas. Na seção que segue, evidenciamos aspectos de uma tarefa desenvolvida à luz da RME que podem ter contribuído para a educação desses jovens em desproteção social, assim como objetivos e/ou competências, da Educação Financeira, desenvolvidos a partir do lidar com a Tarefa 11. A Figura 2 traz as situações que compõem a tarefa discutida.

Figura 2: Fichas da Tarefa 11

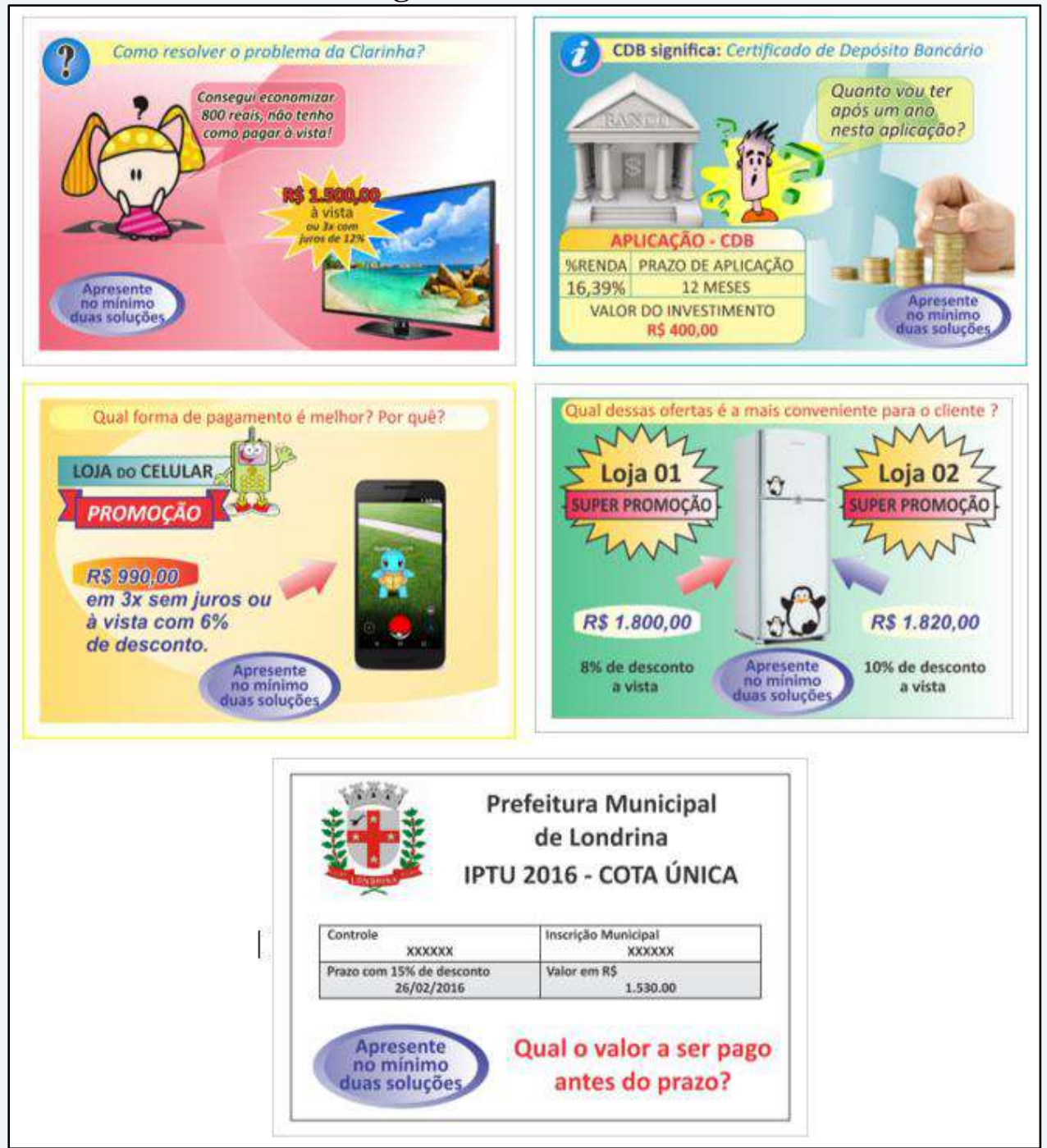

Fonte: (HARMUCH, 2017) 
O Quadro 3 situa os objetivos específicos da Educação Financeira da Tarefa 11, relacionando as competências, com base no Quadro 1.

Quadro 3: Objetivos e Competências da Tarefa.

\begin{tabular}{|c|c|c|c|c|c|c|c|c|c|c|c|}
\hline \multirow{2}{*}{$\begin{array}{l}\text { Nome da } \\
\text { Tarefa }\end{array}$} & \multirow[b]{2}{*}{ Objetivos específicos } & \multicolumn{10}{|c|}{ Competências } \\
\hline & & $\bar{u}$ & $\tilde{U}$ & $\tilde{3}$ & త & in & ש & $\hat{0}$ & $0^{\infty}$ & 己े & 己े \\
\hline $\begin{array}{l}\text { Havia uma } \\
\text { porcentagem } \\
\text { no meio do } \\
\text { caminho. }\end{array}$ & $\begin{array}{l}\text { Comparar valores; } \\
\text { Compreender que não saber fazer } \\
\text { cálculos de porcentagem pode nos } \\
\text { levar a gastar mais dinheiro; } \\
\text { Tomar decisões em compras; } \\
\text { Identificar se vale a pena aplicar } \\
\text { dinheiro; } \\
\text { Debater a importância de não sonegar } \\
\text { impostos; } \\
\text { Debater direitos e deveres como } \\
\text { consumidor; }\end{array}$ & $\mathbf{X}$ & & $\mathbf{X}$ & $\mathbf{X}$ & $\mathbf{X}$ & $\mathbf{x}$ & $\mathbf{X}$ & $\mathbf{X}$ & $\mathbf{X}$ & $\mathbf{X}$ \\
\hline
\end{tabular}

Fonte: (HARMUCH, 2017)

Ao elaborar as tarefas, foram consideradas as necessidades apresentadas pela Instituição nas duas reuniões realizadas com a direção e a equipe pedagógica: trabalhar as quatro operações matemáticas elementares (adição, subtração, multiplicação, divisão). As atividades foram classificadas como situações realísticas por abrangerem contextos que podem ser imaginados pelos envolvidos.

\section{Uma reflexão da prática vivenciada: Tarefa 11}

Durante o envolvimento da Tarefa 11, na qual participaram 24 jovens, foram formado 5 grupos (4 com 5 estudantes e um com 4 estudantes) e em uma bancada foram dispostas as 5 fichas (conforme Figura 2). Cada grupo pode escolher qual fazer primeiro, porém todos deveriam passar por todas as fichas. O propósito das cinco fichas no campo da Educação Financeira era levar a reflexões de objetivos propostos no Quadro 1, já no campo da matemática o objetivo eram propor soluções por meio do uso de cálculos básicos e diferentes maneiras de calcular porcentagem.

A professora observou cada um dos cinco grupos e fez intervenções por meio de questionamentos. Intervir é um recurso que o professor tem ao guiar a produção de seus alunos, permitindo que eles se reconheçam ativos em seus processos de aprendizagem, mas 
com orientações. Em cada intervenção, a professora buscou ser compreendida por todos os integrantes do grupo; mediar às respostas dos alunos sem apontar como corretas ou incorretas; compreender o raciocínio de cada integrante, assim como de todo o grupo; orientar os raciocínios apresentados pelos alunos. Essas características são reconhecidas por Santos (2008) como potencializadoras do processo de aprendizagem.

O planejamento da tarefa foi primordial. Um professor que busca intervir na aprendizagem dos seus alunos "precisa ter clareza de suas intenções educativas e de seu planejamento de trabalho, escolhendo conteúdos, métodos aplicados e instrumentos coerentes com suas intenções" (MENDES, 2014).

Após o tempo combinado, os alunos organizaram-se para compartilhar e construir estratégias com o grupo todo. Nesse momento, apresentaram soluções distintas, evidenciando que as situações que compunham a tarefa eram realísticas, para os sujeitos que as resolveram, e flexíveis, uma vez que permitiram aos alunos resolverem por diferentes estratégias e em diferentes níveis de compreensão (FERREIRA, 2013).

A discussão no grande grupo iniciou-se pela ficha (situação) que envolve a compra de um celular. Os jovens a consideraram mais fácil que as demais. Em todos os grupos, uma das estratégias escolhidas para lidar com a situação foi realizar a multiplicação de 6 por 990 e dividir o resultado por 100 .

Figura 3: Exemplo de produção da ficha do celular

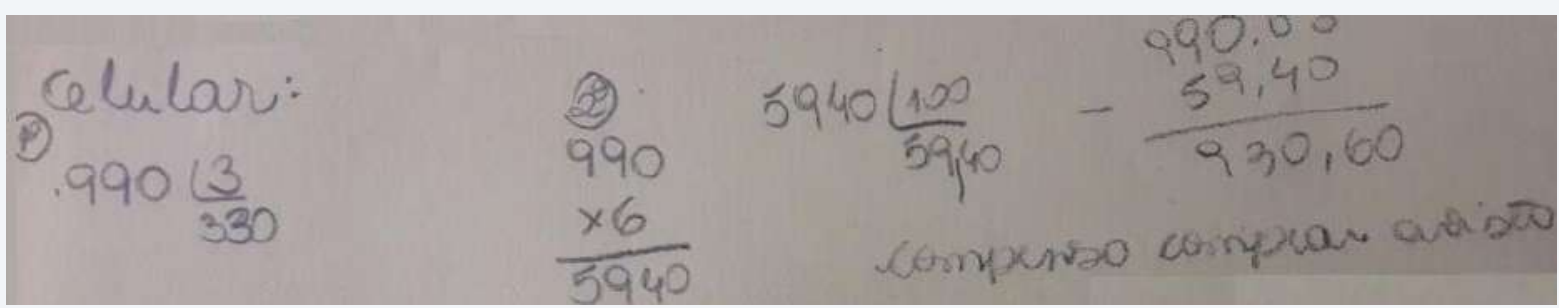

Fonte: autoras

Como foram solicitadas duas estratégias para resolver cada uma das propostas, a professora questionou se havia outra forma de descobrir o desconto. Os alunos ficaram em silêncio, até que um respondeu que poderia ser feito por meio da "regra de três" (proporção). A seguir, apresentamos a transcrição de um trecho da discussão que evidencia uma oportunidade para discutir as ideias matemáticas envolvidas na situação.

A5- [...] mas gente fazer pela regra de três é a mesma coisa de fazer daquele jeito! (Referindo-se ao cálculo de multiplicar o 990 por 6 e na sequência dividir por 100). 
A22 - É mesmo, olha só! Mas então não precisa fazer regra de três. É só multiplicar, daí divide por 100 .

$\mathrm{P}^{6}$ - Vocês sabem calcular de cabeça o $1 \%$ e o $10 \%$ ? (Consentiram).

$\mathrm{P}$ - Então, como ficaria $10 \%$ de 600 , por exemplo?

Alguns exclamaram: -60 ué! Né?

$\mathrm{P}-\mathrm{E}$ se fosse $1 \%$ de $600 ?$

Alguns alunos exclamaram: - Acho que 6. É seis, sim!

$\mathrm{P}$ - Sabendo disso, é possível fazer de outra forma o cálculo de porcentagem?

Alunos - Silêncio.

A6 - Professora! Se $1 \%$ de 990 é $9,9 \ldots$ daí é só multiplicar por quantos $1 \%$ que quer...assim: 9,9 vezes 6. Não é?

$\mathrm{P}$ - Será? Como podemos fazer para ter certeza?

Alunos: Vendo, né professora?

A4 - Pega a calculadora aí A1.

A1 - Que que é para fazer?

A4 - Faz aí, 6 vezes 9,9.

$\mathrm{A} 1-59,4$.

A6 - Eu não falei!

Alguns alunos balbuciam: Porque não falaram que era assim antes? Só fazer $1 \%$ e multiplicar?

A2 - Professora, eu posso tirar foto desse jeito aí? Vou fazer só desse jeito.

A15 - Não acredito que é tão fácil assim!

P - Ok! Há muitas maneiras de se pensar o como calcular uma determinada porcentagem.

A2 - Professora, vamos fazer o da geladeira (proposta verde) desse jeito (referindose à maneira de pensar em $1 \%$ primeiramente)?

P - Vamos sim, mas quero esgotar outras maneiras de resolver isso. Há outras maneiras de se pensar sobre qual forma de pagamento é melhor.

A22 - À vista, né professora, mas se não tem todo o dinheiro então tem que parcelar...eu não aguento ficar sem celular!

A5 - ... ou esperar outro mês para juntar mais dinheiro.

\footnotetext{
${ }^{6}$ Prefere-se a professora pesquisadora.
} 
A professora, ao solicitar outros modos de realizar o cálculo de porcentagem e permitir que socializem esses caminhos, oportuniza que reflitam acerca da própria estratégia. Essa discussão também favorece que, para além de decisões restritas a resultados matemáticos, os alunos reflitam nas competências financeiras para que, embasados em suas realidades, seus planejamentos, suas necessidades, decidam como proceder. A matemática nesse lidar com a situação não tem um fim em si mesma, é uma ferramenta para fundamentar a solução.

O contexto da Tarefa mostrou ser de interesse dos estudantes, que estavam envolvidos com o tema. Conforme pressupõe a perspectiva da RME, a tarefa deve estar conectada à realidade dos estudantes (VAN DEN HEUVEL-PANHIZEN, 1996).

Ao pedir ao aluno que apresentasse diferentes formas de lidar com a situação, o professor favoreceu que ele buscasse para além de reproduzir algum algoritmo. Exigiu conectar e refletir em como as ideias matemáticas podem ser traduzidas por procedimentos equivalentes, provocando pensar além da forma a que está rotineiramente acostumado. Os jovens sugeriram técnicas de "regra de três" e multiplicação seguida por divisão, depois da discussão eclodiu outra forma de resolver, pensar em $1 \%$ para depois multiplicar a porcentagem desejada.

A interação dos alunos uns com os outros, o fato de terem a oportunidade de analisar e discutir são também aspectos da dinâmica de uma aula desenvolvida à luz da Reinvenção Guiada. O conhecimento se constrói no social (GRAVEMAIJER, 2005), a interação é um dos princípios da RME.

Saber fazer um cálculo de porcentagem para determinar preços a pagar não garante tomar decisões financeiras certas. No contexto de sala de aula, é preciso que o professor, junto com os alunos, discuta outras estratégias e oportunize olhar todo o contexto, então as ferramentas para a tomada de decisão serão mais conscientes. Quando A5 comentou sobre esperar mais um pouco para adquirir o produto, abriu-se a oportunidade de refletir sobre as competências C03, C06, C08, C09 e C10 (Quadro 1), pois é uma decisão financeira que leva em conta as reais necessidades, harmonizando desejos, que pode contemplar um planejamento financeiro e, ao mesmo tempo, é uma análise de alternativa de prevenção e de alternativas para a superação de dificuldades econômicas.

Após a discutir essa ficha, as demais discussões e soluções que envolviam cálculos com porcentagem foram apresentadas sem técnica de regra de três, mas conforme estratégias descobertas que derivaram da primeira discussão. 
Na tarefa que investiga o capital após um ano de aplicação, para além dos cálculos envolvidos, foram discutidas outras formas de investimentos e aplicação de dinheiro, favorecendo o desenvolvimento de outros objetivos e competências da Educação Financeira, como elaborar um planejamento financeiro, buscando analisar alternativas de prevenção em longo prazo e superação de dificuldades econômicas (C08, C09 e C10).

Na tarefa que se refere à taxa de IPTU, discutiram-se os porquês e a importância de pagar impostos. Embora na tarefa não esteja explícita a necessidade de realizar essa discussão, o contexto e o ambiente permitiram ao professor debater direitos e deveres de cada cidadão (C01).

Outras três competências da Educação Financeira que deriva dessa Tarefa é: uma melhor leitura em relação a publicidade (C04) e (C05) em que o objetivo é fornecer ferramentas para tomadas de decisões autônomas e também não conseguimos dimensionar, se os alunos se tornaram disseminadores das ideias discutidas (C07).

\section{Algumas considerações finais}

Uma vez que as finanças são as maiores inquietudes de um sistema capitalista como o do nosso país, abordar, explorar e/ou investigar uma Educação Financeira são discussões pertinentes, seja essa educação voltada à sala de aula ou a trabalhos acadêmicos, estudos empresariais e governamentais. Muitos brasileiros estão sofrendo pela prática do consumo desenfreado, falta de planejamento e pela falta de informação, o que gera problemas sérios para si mesmo e para o bem-estar da família.

Salientamos que Educação Financeira não visa ao enriquecimento e sim à conscientização para que as pessoas aprendam a lidar com suas finanças e, talvez, em longo prazo, mudar o quadro econômico pessoal e familiar. Sabemos a importância do papel da Matemática nesse contexto para tomadas de decisões e planejamentos.

As Tarefas tornaram-se motivadoras para os alunos, pois eram realísticas, uma vez que as propostas, lidar com dinheiro e tomar decisões financeiras, fazem parte de nossas vidas. Uma tarefa contextualizada, que parte do universo real do aluno e está conectada com os problemas autênticos da vida cotidiana, é uma das características da RME.

Nem sempre o rumo que a tarefa toma está previsto no planejamento, como aconteceu com a que envolvia a Taxa de IPTU ao se discutir a importância dos impostos, porém isso pode ser convertido novamente em oportunidades de aprendizagem, que é um dos 
princípios da RME, que possa ser de valor humano, além de oportunizar desenvolvimento de competências do letramento matemático nas intenções de estimular um cidadão construtivo, interessado e reflexivo.

A Sequência de Tarefas, em particular a Tarefa 11, é composta por situações que podem serem resolvidas, decididas simplesmente por uma escolha pessoal, entretanto, o professor, enquanto sujeito que guia e acompanha seus alunos, instiga e questiona a produção do aluno, fazendo com que essa escolha seja refletida e justificada.

Por meio das intervenções da professora, os alunos desempenharam papéis de protagonista em seus processos de aprendizagem em um contexto baseado nas suas próprias produções e nas interações entre os colegas de sala. Em nossa pesquisa, escolhemos a RME como abordagem de ensino por reconhecermos nela nossos princípios de ensino e de aprendizagem. Ressaltamos que as tarefas propostas em Harmuch (2017), em particular a apresentada neste artigo, podem ser desenvolvidas em uma sala de aula regular de matemática, mas consideramos fundamental que seja dado oportunidade ao aluno de construir e partilhar suas estratégias, por acreditarmos que é nessa interação que as competências da Educação Financeira serão desenvolvidas, e favorecer aos alunos reconhecer as ideias matemáticas como ferramentas para lidar com as situações que requerem decisões em contextos financeiros.

Os dados da pesquisa permitem inferir que, em relação ao modelo pedagógico para orientar o ensino de Educação Financeira, o lidar com a Tarefa 11 gerou um ambiente pedagógico propício para discutir aspectos dos 7 objetivos propostos no Quadro 1. Especificamente: OB1 - ao discutir os impostos que são pagos pelo cidadão, permitiu refletir sobre a necessidade de cada cidadão reconhecer seus deveres, como também lutar por seus direitos (educação, saúde, segurança); OB2 - quando o aluno sugeriu esperar um pouco mais para adquirir o produto, levou em conta harmonizar desejos e necessidades no planejamento financeiro do projeto de vida; OB3 - ao reconhecer porcentagem como uma ferramenta para determinar o valor real de um produto (ferramentas para tomada de decisão autônoma); OB4 - ao oportunizar que as informações discutidas fossem disseminadas para seus familiares; OB5 e OB6 - ao buscar formas de investir e/ou aplicar o dinheiro, analisar situações em curto, médio e longo prazos (formas de analisar alternativas de prevenção e equilíbrio financeiro); OB7 - ao analisar alternativas para superar dificuldades econômicas, na busca de estratégias para poupar um pouco mais na compra de qualquer produto. 
Uma intenção subjacente a este trabalho é a de servir como uma forma de originar novas experiências comprometidas com a própria Educação Financeira que evidenciem os conceitos matemáticos, estruturas, ideias como ferramentas para organizá-los.

\section{REFERÊNCIAS}

BRASIL/COREMEC.Educação Financeira nas escolas: Ensino Médio. Bloco 1 (Livro do professor). COREMEC, GAP, UNIBANCO, 2010.

BRASIL/ENEF. Estratégia nacional de Educação Financeira: Plano Diretor da ENEF: Anexos,2011. Acedido em 05 novembro 2011 em http://www.vidaedinheiro.gov.br/Legislacao /Arquivo/Plano-Diretor-ENEF-anexos-1.pdf

CIANI, Andréia Büttner.O realístico em questões não-rotineiras de matemática. 2011. 166f. Tese (Programa de Pós-Graduação em Ensino de Ciências e Educação Matemática) Universidade Estadual de Londrina, Londrina. 2012.

DE LANGE, Jan. Mathematics for Literacy. In: MADISON, Bernard; STEEN, Lynn (eds). Quantitative Literacy: Why Numeracy Matters for Schools and Colleges. Princeton, New Jersey: National Council on Education and the Disciplines, p. 75 - 89, 2003.

ESTATUTO DA CRIANÇA E DO ADOLESCENTE, Lei nº 8.069, de 13 de julho de 1990.

FERREIRA, Pamela Emanueli Alves. Enunciados de Tarefas de Matemática: um estudo sob a perspectiva da Educação Matemática Realística. 2013. 121f. Tese (Doutorado em Ensino de Ciências e Educação Matemática) - Universidade Estadual de Londrina, Londrina, 2013.

FREUDENTHAL, Hans. Geometry between the devil and the deep sea. Educational Studies in Mathematics. Holanda, v. 3, n. 3-4, p. 413-435, 1971.

FREUDENTHAL, Hans. Matemática nova ou educação nova? Perspectivas, Portugal, v. 9, n.3, p. 317-328, 1979

FREUDENTHAL, Hans. Revisiting mathematics education. Netherlands: Kluwer Academic Publishers, 1991.

GRAVEMEIJER, Koeno. O que torna a matemática tão difícil e o que podemos fazer para o alterar?. Educação matemática: caminhos e encruzilhadas. Lisboa: APM, p. 83-101. 2005.

HARMUCH, Daniela. Tarefas para uma educação financeira: um estudo. Dissertação de Mestrado - Universidade Tecnológica Federal do Paraná, Londrina, 2017.

HOFMANN, Ruth, MORO, Maria Lucia Faria. Educação matemática, contexto e educação financeira. In: XIII Conferência Interamericana de Educação Matemática- CIAEM, Recife, Pernambuco, p.1-8, 2011. 
MENDES, Marcele Tavares. Utilização da Prova em fases como recurso para aprendizagem em aulas de Cálculo. 2014. Tese (Doutorado em Ensino de Ciências e Educação Matemática) - Universidade Estadual de Londrina, Londrina, 2014.

SANTOS, Edilaine Regina. Análise de produção escrita em Matemática: de Estratégia de avaliação a estratégia de ensino. 2014. Tese (Doutorado em Ensino de Ciências e Educação Matemática) - Universidade Estadual de Londrina, Londrina. 2014.

SANTOS, Leonor. Dilemas e desafios da avaliação reguladora. In Luiz Menezes; Leonor Santos; Helena Gomes; Cátia Rodrigues (Eds.), Avaliação em matemática: problemas e desafios. Viseu: Secção de Educação Matemática da Sociedade Portuguesa de Ciências de Educação, p.11-35, 2008.

VAN DEN HEUVEL-PANHUIZEN, Marja Van Den. Learning-teaching trajectories with Intermediate attainment targets. In: VAN DEN HEUVEL-PANHUIZEN, Marja (Ed.). Children learn mathematics: a learningteaching trajectory with intermediate attainment targets for calculation with whole numbers in primary school. Groningen, The Netherlands: Wolters Noordhoff, 2001.

VAN DEN HEUVEL-PANHUIZEN, Marja Van Den. Assessment and realistic mathematics education. FreudenthalInstitute, Utrecht, 1996.

\section{SOBRE AS AUTORAS:}

\section{Daniela Harmuch}

Doutoranda do Programa de Pós-graduação em Ensino de Ciências e Educação Matemática da Universidade Estadual de Londrina. Mestre em Ensino de Matemática pela Universidade Tecnológica Federal do Paraná (UTFPR) campus de Londrina, PR, Brasil. E-mail: dharmuch@yahoo.com.br

\section{Marcele Tavares Mendes}

Doutora em Ensino de Ciências e Educação Matemática pela Universidade Estadual de Londrina. Docente do Departamento de Matemática e do Programa de Mestrado Profissional em Ensino de Matemática - Universidade Tecnológica Federal do Paraná (UTFPR), campus Londrina. E-mail: marceletavares@utfpr.edu.br 